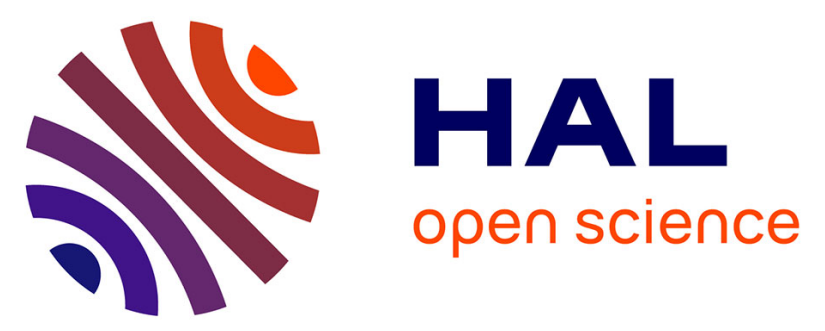

\title{
Inverse modeling of surface NO x anthropogenic emission fluxes in the Paris area during the Air Pollution Over Paris Region (ESQUIF) campaign
}

\author{
Isabelle Pison, Laurent Menut, Gilles Bergametti
}

\section{- To cite this version:}

Isabelle Pison, Laurent Menut, Gilles Bergametti. Inverse modeling of surface NO x anthropogenic emission fluxes in the Paris area during the Air Pollution Over Paris Region (ESQUIF) campaign. Journal of Geophysical Research, 2007, 112 (D24), 10.1029/2007JD008871 . hal-02326117

\section{HAL Id: hal-02326117 \\ https://hal.science/hal-02326117}

Submitted on 22 Oct 2019

HAL is a multi-disciplinary open access archive for the deposit and dissemination of scientific research documents, whether they are published or not. The documents may come from teaching and research institutions in France or abroad, or from public or private research centers.
L'archive ouverte pluridisciplinaire HAL, est destinée au dépôt et à la diffusion de documents scientifiques de niveau recherche, publiés ou non, émanant des établissements d'enseignement et de recherche français ou étrangers, des laboratoires publics ou privés. 


\title{
Inverse modeling of surface $\mathrm{NO}_{x}$ anthropogenic emission fluxes in the Paris area during the Air Pollution Over Paris Region (ESQUIF) campaign
}

\author{
Isabelle Pison, ${ }^{1}$ Laurent Menut, ${ }^{2}$ and Gilles Bergametti ${ }^{1}$ \\ Received 23 April 2007; revised 5 July 2007; accepted 20 August 2007; published 21 December 2007. \\ [1] An inverse modeling approach has been developed to optimize urban $\mathrm{NO}_{x}$ emission \\ fluxes. We used the chemistry-transport model CHIMERE and its adjoint to develop \\ a new methodology that includes kriging of measurements and a dynamic spatial \\ aggregation model taking into account surface morphology of emission fluxes and ozone \\ plumes to determine areas where emissions are inverted. This method is first applied \\ to a seasonal approach over the Paris area. All emission fluxes were inverted hourly for the \\ months of July and August of years 1998 and 1999. This leads to a significant reduction \\ of the differences between simulated and measured concentrations of ozone and $\mathrm{NO}_{x}$. \\ The results suggest that in the first-guess inventory, $\mathrm{NO}_{x}$ fluxes are overestimated in the \\ city of Paris and underestimated in the suburban areas. For the two periods the \\ differences between optimized and first-guess profiles are about $15 \%$. Comparisons \\ between time profiles showed that Mondays and Wednesdays in August had \\ characteristics that made them differ from the other days of the week. Two intensive \\ observation periods of the Air Pollution Over Paris Region (ESQUIF) campaign are \\ focused on and hourly results are discussed in order to refine the climatological results.
}

Citation: Pison, I., L. Menut, and G. Bergametti (2007), Inverse modeling of surface $\mathrm{NO}_{x}$ anthropogenic emission fluxes in the Paris area during the Air Pollution Over Paris Region (ESQUIF) campaign, J. Geophys. Res., 112, D24302, doi:10.1029/2007JD008871.

\section{Introduction}

[2] In an urban scale atmospheric pollution context, the underlying temporal and spatial scales range from a day to a week for a domain of about $\sim 100 \times 100 \mathrm{~km}$. The quality of simulated concentrations at these scales is directly linked to the quality of the emission inventory. These inventories are often created using a "bottom-up" approach: given the intensity and the rate of activity of individual emission sources, data are aggregated on them. Thus it is necessary to manage many different kinds of data, each of them often associated with large uncertainties. For example, over Europe, the EMEP data (www.emep.int) are provided as annual emitted masses per activity sectors and for a specific horizontal resolution. Such data have to be preprocessed before being used by chemistry-transport models because the input information required by models is expressed in surface emission flux per model chemical species. In addition, they have to be interpolated spatially and temporally in order to adjust models' resolution. The resulting product is a model inventory, hereafter called the "firstguess inventory."

\footnotetext{
${ }^{1}$ Laboratoire Inter-Universitaire des Systèmes Atmosphériques, Université Paris 12-CNRS, Créteil, France.

${ }^{2}$ Institut P.-S. Laplace, Laboratoire de Météorologie Dynamique, École Polytechnique, Palaiseau, France.
}

Copyright 2007 by the American Geophysical Union. 0148-0227/07/2007JD008871\$09.00
[3] Moreover, the continuously changing nature of these emissions spatially, temporally, chemically and physically makes the update of inventories particularly difficult [Kühlwein and Friedrich, 2000]. Obviously, a better knowledge of emission fluxes would lead to better simulations of concentration fields and thus to a better understanding of photo-oxidant pollution events. Moreover, in the framework of the evaluation of prospective scenarios an improved estimate of past and present emissions constitutes a more reliable basis.

[4] The aim of the optimization of emissions is to derive an inventory that minimizes the difference between simulated and measured concentrations. Such a method is referred to as "inverse approach" because it uses available observations concerning model outputs in order to correct input parameters. The results consist of correction coefficients for each emitted species (or family) of the available inventory.

[5] Inverse methods, derived from algorithms belonging to the family of data assimilation [Talagrand and Courtier, 1987; Talagrand, 1997], have been used in various fields, such as meteorology and more recently atmospheric chemistry [Enting, 2002]. They have been especially useful at the global scale for estimating emissions of species having long lifetimes such as methane [Hein et al., 1997; Houweling et al., 1999; Wang and Bentley, 2002], carbon dioxide [Bousquet et al., 1999; Kaminski and Heimann, 2001; Rödenbeck et al., 2003; Gurney et al., 2005], CFCs [Hartley and Prinn, 1993; Mahowald et al., 1997], and carbon 
monoxide [Bergamaschi et al., 2000; Pétron et al., 2002, 2004; Wang et al., 2004; Müller and Stavrakou, 2005] and, at the continental scale, for nitrogen oxides $\left(\mathrm{NO}_{x}\right)$ [Wang et al., 2004; Konovalov et al., 2005]. Studies dealing with the inversion of emissions at a local scale, in the context of boundary layer pollution, are still scarce. First, we can cite the 1992 measurement campaign in the Atlanta area, leading to studies on the inversion of isoprene [Chang et al., 1996], carbon monoxide [Chang et al., 1997], and ozone precursors such as volatile organic compounds (VOCs) and $\mathrm{NO}_{x}$ [Mendoza-Dominguez and Russell, 2001]. Carbon monoxide emissions were also inverted in the Los Angeles area [Mulholland and Seinfeld, 1995]. In Europe, $\mathrm{NO}_{x}$ emissions were inverted in the Lille (France) area [Quélo et al., 2005]. These studies have shown that it was possible to correct emission inventories at a local scale even if the difficulties are numerous and somewhat different from those encountered at a global or continental scale [Enting, 2002], mainly because of the strong nonlinearities of some of the interacting processes.

[6] When the impact of emissions on the final modelled concentrations is investigated at a local scale, the role of transport is compensated by chemistry. Therefore it is possible to use concentration measurements of one species to invert the emissions of its precursors. For example, the use of ozone observations to invert $\mathrm{VOC}$ and $\mathrm{NO}_{x}$ emissions leads to reasonable results provided the number of measurements is high, such as is generally the case during an intense field campaign [Mendoza-Dominguez and Russell, 2001; Quélo et al., 2005]. However, using measurements of secondary species to invert their precursors can generate significant errors due to the uncertainties in the chemical processes described in the model. It is therefore more reliable to use concentration measurements of the same species as the ones to be inverted [Mulholland and Seinfeld, 1995; Chang et al., 1996, 1997] or of species directly linked to them, for example, $\mathrm{NO}$ or $\mathrm{NO}_{2}$ observations for $\mathrm{NO}_{x}$ emissions [Quélo et al., 2005].

[7] The Paris area is well suited for the inversion of emissions at the local scale. First, the layout of the area consists of a dense city with intense emissions, surrounded by gradually less urbanized suburbs to remote rural areas. Moreover, the Paris area is far enough from the coasts and its topography is relatively flat so that the dynamical fields are quite homogeneous and relatively easy to simulate. Thus the influence of the emission inventory on discrepancies between measured and simulated concentrations is directly highlighted. Finally, air quality in the Paris area has been well investigated. First, AIRPARIF's measurement network covers the whole of the area with many stations (39 in 1998 and 48 in 1999) that monitor various chemical species including ozone, $\mathrm{NO}$ and $\mathrm{NO}_{2}$. Second, a large experimental campaign, called ESQUIF (or Air Pollution Over Paris Region), took place in the Paris area during the summers of 1998 and 1999, providing additional information on some specific pollution events [Menut et al., 2000b].

[8] In this paper we first introduce the inverse modeling methodology. A first part of the methodology was developed and validated for the specific case of local-scale inverse modeling. This work has been previously presented in the work of Pison et al. [2006]: its main characteristics are reminded in section 2 . The second part of the new meth- odology is presented in section 3 and introduces a new model of spatial aggregation. In section 4, we apply the new approach over the July and August 1998 and 1999 periods, in order to estimate the main corrections to seasonal surface emission fluxes over the whole domain. In order to refine the seasonal results, specific events are more precisely studied, 7 August 1998 (section 5.1) and 16-18 July 1999 (section 5.2), that correspond both to previously and extensively studied intensive observation periods of the ESQUIF project over the Paris area [Beekmann and Derognat, 2003; Menut et al., 2000b; Menut, 2003; Vautard et al., 2003a]. Finally, conclusions and prospects are presented in section 6.

\section{Methodology and Associated Modeling Platform}

\subsection{Inversion Methodology}

\subsubsection{Cost Function}

[9] The inversion methodology used in this paper was primarily validated on academic cases as described by Pison et al. [2006]. The academic approach was developed step by step, using cases with increasing difficulty levels in order to ensure the validity of the optimized fluxes. The adjoint approach was chosen because the impact of morning emissions of $\mathrm{NO}_{x}$ is being observed on concentrations in the afternoon: the adjoint method can easily take into account the trajectory of the model and the nonlinear links between constraints and parameters at a timescale that suits the lifetimes of the chemical species of interest.

[10] This led to the development of an original methodology: available measurements are being mapped over the domain leading to the best possible constraint for the inversion process. The algorithm used is based on a kriging approach, that is, a specific optimal interpolation, merging measurements and model results to calculate analyzed concentration fields. Pison et al. [2006] showed that adding constraints (i.e., information) on concentrations often yields better results than adding information on the emissions (for which the uncertainty is very large). In this case, the cost function, which represents the distance between observations and simulated concentrations, is

$$
J(\mathbf{e})=\left(\mathbf{y}_{\text {sim }}-\mathbf{y}^{\mathbf{a}}\right)^{T} \mathbf{R}^{-1}\left(\mathbf{y}_{\text {sim }}-\mathbf{y}^{\mathbf{a}}\right)
$$

where $\mathbf{y}^{\mathbf{a}}$ and $\mathbf{y}_{\text {sim }}$ represent analyzed and simulated concentrations, respectively. The $\mathbf{R}$ matrix contains the variances and covariances of the observation errors. In this case, we only have access to diagonal information due to the specificity of the kriging technique. Since information on the first-guess emission fluxes $\mathbf{e}_{\mathbf{b}}$ is embedded in the analyzed concentrations (they depend on the simulated concentration field), the penalization term usually expressed with a "background" matrix is not used in the cost function. Finally, e represents the surface emission fluxes to be optimized and $J$ the associated cost function.

[11] The use of the first-guess inventory to generate the constraints has some advantages. In our framework of local air pollution, it is very difficult to find accurate additional information about first-guess emissions whereas the simulated spatial distribution and time evolution of chemical species have relatively small uncertainties. In this case the model prescribes the structure of the flow (location of the 
plume for example) on the analyzed concentration field, and the measurements modulate the values of the concentrations (increasing ozone in the plume as compared to the firstguess for example). The resulting constraints are at the time and space resolution of the model. The main drawback is that the constraints are not totally independent from the model as is usually the case.

\subsubsection{Direct and Adjoint Integrations}

[12] The optimization consists in minimizing $J$ with regard to $\mathbf{e}$. The adjoint approach was chosen for performing this minimization because it easily accounts for the trajectory of the model and performs four-dimensional (4-D) integration [Talagrand, 1997; Enting, 2002; Daescu et al., 2003; Sandu et al., 2003]. The value $J(\mathbf{e})$ is thus computed by the direct model and its gradient $\partial J / \partial \mathbf{e}$ by the adjoint in one single backward-in-time run. The gradient is then used to determine a new e of corrected emissions, which minimizes $J$. This direct-adjoint cycle is iterated until a minimal cost value is obtained. In practice, a stopping criterion is defined to stop the iterations when the chosen precision is reached: formally, a minimal value to be defined between measurements and modelled concentration. In our case, the criterion is the ratio between the norms of the gradient at the current and at the initial points. Its value is thus the fraction in which the norm of the gradient has to be reduced by the optimization. On the basis of physical considerations, a difference of less than $0.1 \mathrm{ppb}$ between two mixing ratios and a correction of less than $1 \%$ for emissions are considered not significant. This led to considering a value taking into account the norm of the gradient as well as the size of the problem and the variances of the analysis [Pison et al., 2006]. Note that the assumptions made here are used to compute a suitable stopping value for the convergence, it does not mean for example that optimized mixing ratios are less than $0.1 \mathrm{ppb}$ from the constraints. If the convergence criterion is not matched in a given number of iterations (chosen so that the computing time is less than one day on an ordinary PC [Pison et al., 2006]), the optimization stops even though convergence is not reached and the results cannot be used. The optimized concentrations provided by the inverse are used to perform a new kriging analysis. The new analyzed concentrations are then used as constraints for a second inversion. Iterating two kriging-inversion cycles refines the results of the optimization as showed in the work of Pison et al. [2006].

\subsection{Modeling Tools}

\subsubsection{Chemistry-Transport Model}

[13] The model used is the gas-phase version of CHIMERE chemistry-transport model [Vautard et al., 2001] and its adjoint. This model has been used to study pollution within the atmospheric boundary layer at a local and a European scales. Both long-term [Schmidt et al., 2001; Vautard et al., 2001] and pollution event [Schmidt and Martin, 2003; Beekmann and Derognat, 2003] simulations can be proceeded, as well as impact studies [Pison and Menut, 2004]. CHIMERE is also part of the French national air quality forecasting system PREVAIR (www.prevair.org/ en/). The version of CHIMERE used in this study covers a domain of $150 \times 150 \mathrm{~km}^{2}$ centered on Paris with $25 \times 25$ cells on eight vertical levels up to $750 \mathrm{hPa}$ and the meteorological data are provided by the ECMWF. The boundary conditions for this domain are provided by a CHIMERE simulation covering Western Europe. The adjoint of CHIMERE has been developed and used for sensitivity studies by Menut et al. [2000a] and Menut [2003]. The minimizer used together with the adjoint is the N1QN3 algorithm by Gilbert and Lemaréchal [1989].

[14] Before inverting the emissions, it is necessary to study whether the discrepancies between simulated and measured concentrations are due to uncertainties in the emission inventory or to other reasons. For each summer since year 2003, statistical comparisons are performed between surface measurements and model outputs of ozone and $\mathrm{NO}_{x}$ with CHIMERE (in the framework of PREVAIR forecast system). Results showed that the model is able to reproduce long-term pollution over various areas as well as the major observed pollution events. This means that for the following seasonal study, the model is not biased and estimates correct mean concentrations. We can then optimize the surface emissions, following the conclusion of Menut [2003] that showed that emissions are the processes to which ozone and nitrogen oxides are the most sensitive over the Paris area.

\subsubsection{Kriging Approach}

[15] The kriging technique used here is called "INK" (for Innovations Kriging) and was primarily developed by Blond et al. [2003] to obtain NO and ozone analyzed concentration maps. This technique uses at the same time the spatially dispersed measurements and the first-guess simulation. Their combination provides an analyzed concentration field, that is, a modelled field integrating the measurements. At any given hour, for any location $\mathbf{s}$, the analysis $y^{a}(\mathbf{s})$ is a correction of the CHIMERE simulation $y^{b}(\mathbf{s})$ by a linear combination of the innovations $y^{o}\left(\mathbf{s}_{\mathbf{k}}\right)-y^{b}\left(\mathbf{s}_{\mathbf{k}}\right)$. $\mathbf{s}_{\mathbf{k}}$, with $\mathrm{k}=$ $1, \ldots, \mathrm{K}$ corresponds to the locations of the measurement values $y^{o}\left(\mathbf{s}_{\mathbf{k}}\right)$ provided by the monitoring stations. "Analysis variances" are computed at the end of the process, using the same weighting functions as the ones used for combining the innovations into the analysis. The INK technique and CHIMERE have been continuously validated since 2003 in the framework of PREVAIR and are used daily by AIRPARIF to produce operational forecast ozone maps (www.airparif.org).

\subsection{Measurements and Emission Inventory}

\subsubsection{Surface Measurements}

[16] The measurements used in this study are those performed by the AIRPARIF network and are described by Menut et al. [2000b]. Four types of measurement stations are available: "rural" and "urban" stations monitor concentrations in rural and urban areas, "traffic" stations measure concentrations at key locations for road traffic, such as big crossings or avenues and "observation" stations perform particular measurements for use in research. The "observation" and "traffic" stations representativity is too low and thus not appropriate to our needs. Therefore only the "rural" and "urban" stations are used. In this study, NO measurements are provided by 19 stations in 1998 and 1999 with a time resolution of $1 \mathrm{~h}$.

\subsubsection{Model Emissions}

[17] The emission inventory used in this paper was primarily elaborated to simulate the most important pollution events recorded during the ESQUIF campaign (1998- 
1999). Total annual masses were provided by EMEP classified to eleven SNAP activity sectors (with SNAP for "Selected Nomenclature for Sources of Air Pollution"). This includes (1) 203 big point sources (industrial chimneys, power plants for example), (2) linear sources (big roads, highways for example), and (3) surface sources such as household heating, diffuse road traffic, and small industrial sources. These annual masses are temporally redistributed using "weekday," "Saturday," and "Sunday or holiday" and hourly functions. For the specific case of August, and after the analysis of Vautard et al. [2003b], the emissions intensities are chosen as those of July with a factor of 0.8 . From these masses, the emission fluxes (molec $\mathrm{cm}^{-2} \mathrm{~s}^{-1}$ ) are redistributed into 16 emitted species or families $\left(\mathrm{CO}, \mathrm{SO}_{2}, \mathrm{CH}_{4}, \mathrm{NO}_{x}\right.$ speciated in $10 \%$ of $\mathrm{NO}_{2}$ and $90 \%$ of NO, HONO and nonmethanic VOCs speciated into 10 subfamilies) and over the model domain mesh. We have to note that road traffic is the main source of $\mathrm{NO}_{x}$ (53\% of all the emissions) and road traffic together with solvents are the main sources for VOCs (35 and $36 \%$ each).

\section{Spatial Aggregation}

\subsection{Ill-Constrained Problem}

[18] The main innovation presented in this paper is the addition of a spatial aggregation algorithm. Even with kriging constraints and despite the high density of measurements performed by AIRPARIF, the available quantity of information remains limited to correctly invert the emissions: this is by definition an ill-constrained problem to solve.

[19] Before the inversion, it is necessary to reduce the freedom degrees of the problem: a possible way is to cluster grid cells having the same characteristics (in term of surface emission fluxes and pollutant concentrations). For example, in the Paris area's inventory, and for each hour, the number of individual fluxes is very high: 625 surface fluxes for each emitted species or family leading to a numerical problem too large to be solved.

[20] The principle of regrouping cells (i.e., defining "zones") was previously used in global inverse modeling studies. Various criteria, mostly geographical, were used to define the zones covering continents or parts of the oceans: Bousquet et al. [1999] took into account the geographical distribution of the various emission sectors, Prinn and Hartley [1995] used the layout of the available emission measurements and Houweling et al. [1999] simply based their zones on the resolution of their model. The optimization is performed assuming that in each zone, the same correction applies to all aggregated fluxes.

[21] At the local scale, the problem is also ill-constrained. Nevertheless, in this case, the time and space variability of both emissions and concentrations is very high. For global scale studies, geographical criteria may be sufficient for defining spatial aggregation because in most cases, sources are inverted with concentration measurements of the same species and the major part of the error (except the part due to the emitted flux) is contained in the transport term. In local photo-oxidant pollution, the nonlinear atmospheric chemistry plays a key role together with transport. Thus the definition of zones should take into account (1) the characteristics of emission fluxes themselves and (2) the sensitivity of concentrations to these emissions. A model for defining the number and location of zones has then been elaborated. Owing to the large variability of situations encountered in atmospheric pollution, it has been designed to be very flexible.

\subsection{Design of the Zoning Model}

[22] To build the zoning model, it is necessary to examine whether spatial or time aggregation is the most relevant. In the Paris area, the locations of the sources are perfectly known. On the other hand, the uncertainty on the time profiles of emissions is large [Vautard et al., 2003b]: thus we need to optimize temporal evolution of emission fluxes and not the location of sources.

\subsubsection{Emission Patterns as Constraints}

[23] We consider that fluxes have to be corrected in the same proportion if they are due to the same kind of source (a misestimation on an emission factor logically applies to the whole inventory). However, the information on activity sectors used for the first-guess inventory is not available: the model using fluxes only for model species. Thus a slightly adapted criterion must be used to define zones. In the case of one particular activity sector accounting for the major part of the emissions of one species or family, it is almost equivalent to aggregate fluxes that are close. This is the case for $\mathrm{NO}_{x}$ fluxes in the Paris area, which are mainly due to road traffic in the summer. It is then realistic to assume that intense $\mathrm{NO}_{x}$ fluxes are mostly due to road traffic and have the same errors and uncertainties.

\subsubsection{Concentration Patterns as Constraints}

[24] The sensitivity of the cost function to the emission fluxes has to be taken into account. It was shown that the sensitivity of concentrations to emissions may change sign through time and space: for example, the sensitivity of ozone concentrations to $\mathrm{NO}_{x}$ emissions is negative the former hour and positive for several hours before [Menut, 2003]. The component of the gradient corresponding to a given zone is the sum of sensitivity terms in the form of $\partial J / \partial \mathbf{e}_{i}, \mathbf{e}_{i}$ being the aggregated fluxes. The zones should therefore be defined so that these terms do not compensate each other. Otherwise, a null gradient that is not representative of the problem would be obtained.

\subsubsection{Merging the Ensemble of Constraints}

[25] The definition of spatial areas having similar sensitivities to emissions can be based on the physics of the studied case. In the Paris area, four main areas emerge, according to the wind direction and speed: (1) The very intensely emitting city center, where concentrations are principally determined by the intensity of local emissions, (2) the area upstream this center, where concentrations are mainly sensitive to local (rural) emissions and boundary conditions, (3) the area located directly downstream the city center, that is, in the plume, which is especially sensitive to emissions occurring in the city center, (4) the area located downwind the city center but not in its plume, where concentrations are sensitive to local emissions.

[26] These four big areas are broken into smaller ones for acknowledging the various intensities in the emission fluxes as stated above. Since the sensitivity of concentrations to emissions depends on the meteorological situation, the 


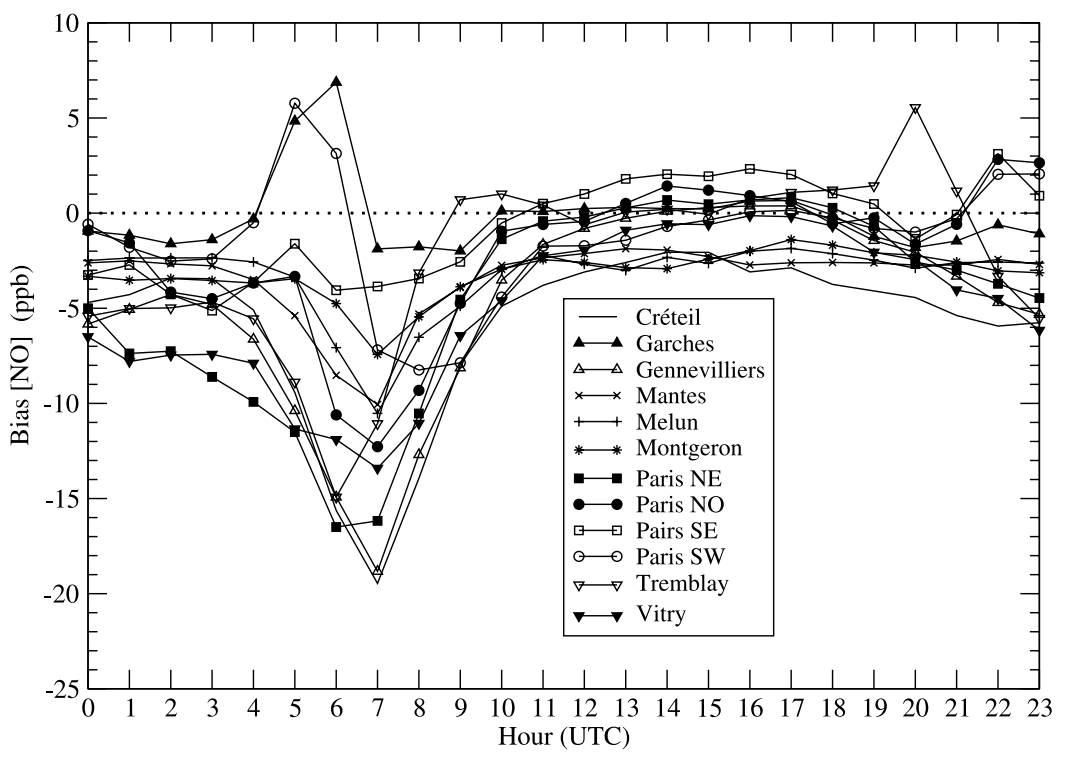

Figure 1. Hourly bias (ppb) between simulated (CHIMERE) and measured (AIRPARIF) NO mixing ratios, computed over July and August 1999 in the urban measurement stations.

aggregation method has to be dynamical: the spatially consistent zones are redefined every hour.

[27] From a numerical point of view, a list of the emission fluxes belonging to each zone is created for each hour. The size of the vector of parameters is then the number of zones and each of its component is the correction coefficient applied to all the fluxes of the corresponding zone.

\subsection{Specific Hypothesis on $\mathrm{NO}_{x}$ Emissions}

[28] It is theoretically feasible to invert surface emissions of all species or families over the whole domain for all hours of the day. However, this leads to a problem with a size that is too big compared to the information available in the constraints and is not always relevant.

[29] In this study, we focus on $\mathrm{NO}_{x}$ emissions because (1) detailed studies of pollution events that occurred in the Paris area (such as Menut et al. [2000b] and Vautard et al. [2003a]) have shown that misestimations of ozone concentrations may be linked to misestimations of $\mathrm{NO}_{x}$ emissions and (2) the information for inversion is provided by $\mathrm{NO}$ concentrations that are directly linked to $\mathrm{NO}_{x}$ emissions. These emissions mainly occur in the morning and at the end of the day during two well-marked peaks of traffic.

[30] To determine a shorter interesting period of time during the day, the bias between NO surface measurements and CHIMERE direct simulations was computed over July and August 1998 and 1999. The results are displayed on Figure 1 as hourly biases for various locations available in 1999. This shows that the bias is significant mainly between 0300 and 1000 in the urban area. We then chose to invert $\mathrm{NO}_{x}$ emissions over this period.

[31] Spatially, the layout of the Paris area makes it possible to further reduce the number of emission fluxes to invert by considering that fluxes less than $5 \times 10^{11}$ molec cm $\mathrm{cm}^{-2} \mathrm{~s}^{-1}$ and located in the rural areas surrounding the domain do not need to be inverted. Their contribution to the development of the photo-oxidant plume actually is small and the uncertainty on these emissions is less important compared to that on the intense urban fluxes. This threshold value leads to the optimization of 30 to 60 fluxes (depending on the meteorological conditions) covering urban and dense periurban areas for each of the $8 \mathrm{~h}$ inversion time window (Figure 2).

[32] Finally, the inventory has been built assuming that the $\mathrm{NO}_{x}$ emitted family is always constituted with $90 \%$ of $\mathrm{NO}$ and $10 \%$ of $\mathrm{NO}_{2}$ [Vautard et al., 2003b]. We consider this ratio as the best approximate for this study and therefore keep it constant in time and space during the inversion.

\section{Seasonal Optimization}

[33] This section aims to a statistical validation of the applied inverse modeling methodology. The basis of this validation is the improvement of predicted concentrations as a result of refined emission inventory and the pointing out overlooked trends. We thus apply the methodology over

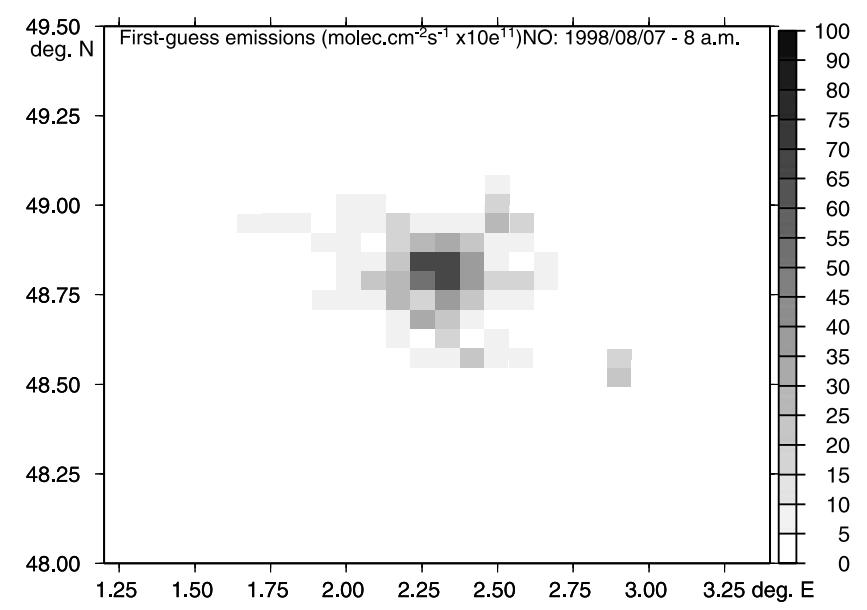

Figure 2. First-guess emission inventory: NO fluxes on 7 August 1998 at 0800. Noninverted fluxes are shown in white, covering rural and periurban areas. 


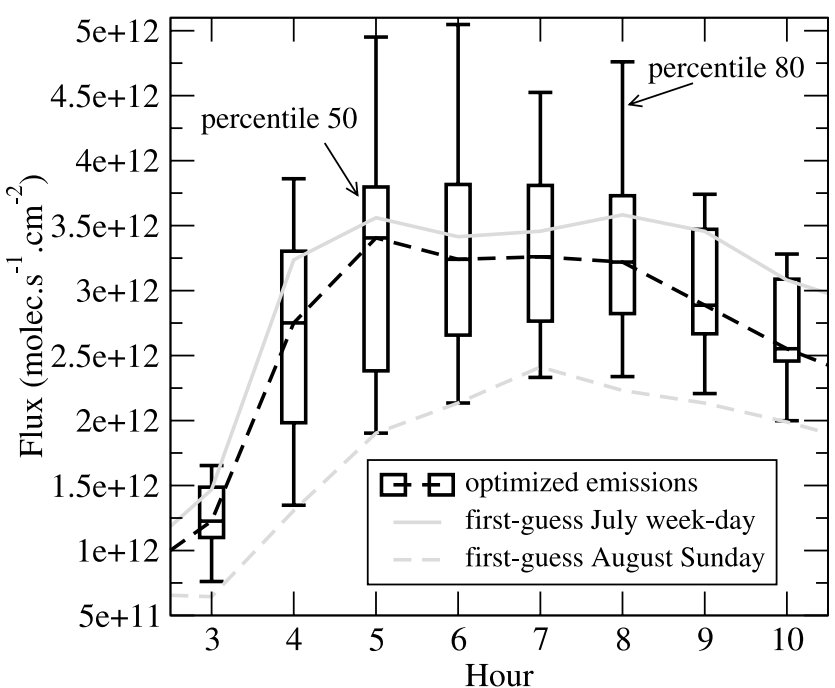

Figure 3. Distribution of NO emission average time profiles over the whole domain around the median for July-August periods of 1998 and 1999 (124 d).

long time periods including both nonpolluted intervals and severe pollution events: the months of July and August 1998 and 1999 that correspond to a total period of $124 \mathrm{~d}$.

[34] The validity of the present study is enhanced by an exhaustive sensitivity analysis [Pison, 2005] of the different parameters that control the predicted concentrations, with special attention to chemical boundary conditions and the boundary layer height. This previous study was based on a four-month statistical analysis and showed the model's efficiency with regards to other parameters suggesting the predominence of the emissions as a control factor. This validates our decision to derive the meteorological data for the simulation from the ECMWF forecast system, as it is currently performed, and proceed to emission inversion.

\subsection{Hourly Variability}

[35] The resulting optimized hourly $\mathrm{NO}_{x}$ emissions are spatially averaged over the domain. Then, for each hour, the median value over the whole period is estimated as well as the distribution of all the optimized time profiles around the median. This result, presented on Figure 3 for NO, are compared to the widest range covered by the six first-guess profiles (delimited by the profiles for weekday in July and for Sunday in August). For weak intensities, the variability of time profiles after the optimization covers the same range as the first-guess ( 80 percentile and first-guess August Sunday profiles). Nevertheless, optimized time profiles cover a range of higher intensities between 0500 and 0800 (80 percentile and first-guess July weekday profiles). A close study of the days corresponding to these profiles show that they occur when the boundary layer height increases very fast between 0500 and 0600 . The sudden diluting of concentrations then sometimes leads to an overcorrection of emissions.

[36] From 0300 to 1000 , the 50 percentile includes optimized fluxes varying from -51 to $+56 \%$ around the median. This variability is a little higher than the a priori variability embedded in the first-guess inventory, which gives a -52.5 to $+20.7 \%$ variability for the two extreme time profiles at the same hours. Note that when the days for
July and August are considered separately, the difference between the corresponding median time profiles varies between $-19,5 \%$ and $-22 \%$. This shows that the choice of the global $-20 \%$ scaling that was applied in the firstguess is suitable for most of the days.

\subsection{Optimization of Each Day Type}

[37] Figure 4 displays time series of the median emission fluxes for each day type (weekday, Saturday, and Sunday) for the first guess and the optimized surface NO emissions.

[38] For weekdays (Figure 4a), the intensity of the emissions is increased after optimization by 9.4 to $17.7 \%$ between 04:00 and 10:00 leading to a global increase of $13.1 \%$ of the total emitted mass. This increase is quite homogeneous in
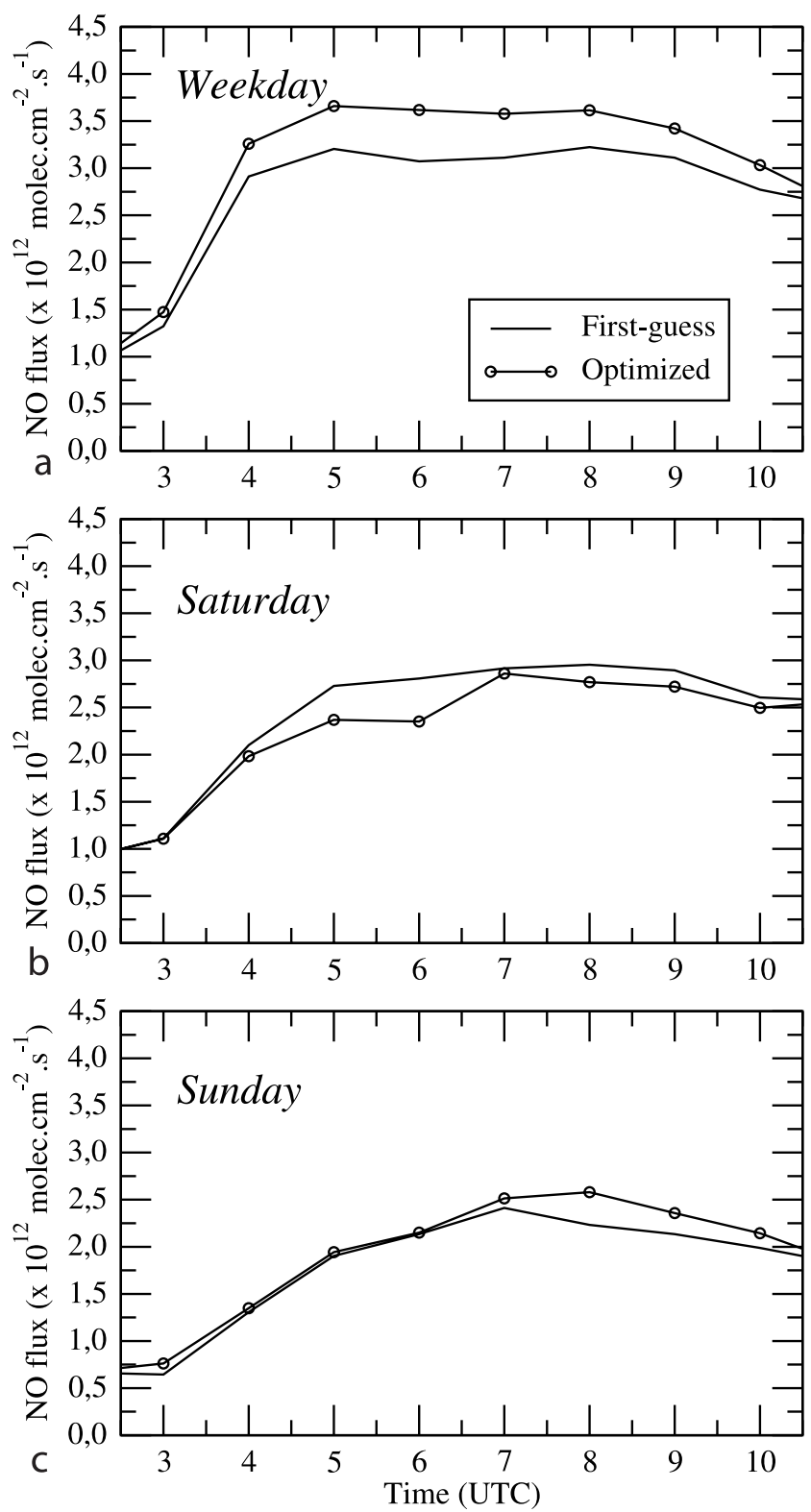

Figure 4. Median optimized and first-guess time profiles of NO emissions for the three types of day over JulyAugust periods of 1998 and 1999. Median values are obtained on 86 weekdays, 18 Saturdays, and 20 "Sundays or holidays." 
time, the general shape of the profile is not changed after optimization. This seems consistent with the good phasing in time of NO concentrations suggested by the correlations between the model and the observations obtained in urban areas (more than 0.65 for all hours of the 124 days).

[39] On Saturday (Figure 4b), the intensity of optimized emissions is decreased by 1.9 to $16.3 \%$ between 0400 and 1000 as compared to the first-guess emission inventory. Consequently, the total emitted mass is reduced by $7.7 \%$. The optimized time profile displays a peak (fluxes more than $2.5 \times 10^{12}$ molec cm $\mathrm{c}^{-2} \mathrm{~s}^{-1}$ ) between 0700 and 0900 , whereas the first-guess fluxes are almost constant (from 2.7 to $2.9 \times 10^{12}$ molec $\mathrm{cm}^{-2} \mathrm{~s}^{-1}$ ) between 0500 and 0900 .

[40] On Sunday (Figure 4c), the intensity of emissions is increased by 15.6 and $10.5 \%$ at 0800 and 0900 , respectively, but is changed by less than $5 \%$ from 0400 to 0700 . The total emitted mass is therefore increased by less than $7 \%$ as compared to the first-guess. The median optimized profile for "Sunday or holiday" is derived from 18 Sundays plus 14 July 1999 and 1998 and 15 August 1998 which are holidays in France. One out of six of these days corresponds to particular situations for road traffic: for example, Tuesday, 14 July 1998 was a return day after an extended weekend.

[41] Finally, even though the uncertainty on the firstguess time profiles for "Saturday" and "Sunday or holiday" types is very large, the characteristics of the optimized profiles remain close to them on the average. Moreover, the changes in the total emitted mass match the results that were obtained during the assessment of the emission inventory, which was led during the ESQUIF campaign with airborne measurements [Menut et al., 2000b; Vautard et al., 2003b]. The overall error on $\mathrm{NO}_{x}$ emissions had thus been estimated to reach $30 \%$ at the most with a confidence level of $95 \%$ [Vautard et al., 2003b].

\subsection{Characterization of Weekdays}

[42] In the previous section we discussed correction coefficients in the framework of the first-guess inventory, with only three types of days (weekday, Saturday, and Sunday). Nevertheless, the optimization makes it possible to further examine whether the regrouping of weekdays under one type is relevant.

[43] On Figure 5, the differences (in percent) between the median optimized profile for each weekday and the median optimized profile of the "weekday" type are displayed. Since road traffic differs in July and August, the two months are compared separately. The 124-d period includes eight Mondays in July and 10 in August, 10 Thursdays in July and eight in August, 10 Fridays in July and eight in August, seven Tuesdays in July and nine in August, eight Wednesdays in July and eight in August.

[44] In July, median time profiles for Mondays, Tuesdays, Thursdays, and Fridays have the same characteristics as the weekday profile: the maximum difference is $3.4 \%$ at $03: 00$ on Thursday (Figure 5). In August, median time profiles for Tuesdays, Thursdays, and Fridays have the same characteristics as the weekday profile: the maximum difference is $-6.9 \%$ at 0600 on Tuesday (Figure 5). The major part of the differences observed on Figure 4 may thus be attributed to changes on Wednesdays.

[45] On Wednesdays in July, the time profile is close to the weekday profile (differences less than $2.5 \%$ ) except at
0600 with a difference of $+5.6 \%$ (Figure 5). Thus emission fluxes on Wednesdays are not almost constant from 0500 to 0800 as is the case for the weekday profile: at 0600 , a peak at more than $3.9 \times 10^{12}$ molec cm$~_{-2} \mathrm{~s}^{-1}$ occurs.

[46] On Wednesdays in August, the time profile follows the same evolution as the weekday profile but the intensity from 0400 to 0800 increases from 0.8 to $8.3 \%$.

[47] Mondays in August also display particular features. Their time profile is close to the weekday profile (absolute differences less than $3.2 \%$ ) but between 0400 and 0500 a difference of +11.2 and $+18.5 \%$ arises (Figure 5). Thus at 0500 , a peak at $\sim 3.7 \times 10^{12}$ molec $\mathrm{cm}^{-2} \mathrm{~s}^{-1}$ occurs. Particular road traffic may explain this difference: for four out of 10 Mondays for August (on 3 and 31 August 1998 and on 2 and 30 August 1999), increased road traffic, probably due to holidays, occurred. Similarly, pronounced road traffic,due to the end of extended weekends probably occurred on two more cases (on 17 August 1998 and 16 August 1999 following the holiday of 15 August).

[48] Finally, the characteristics of the five individual days of the week are not very different from the characteristics of the mean weekday, except for Wednesdays and the ambiguous case of Mondays in August.

\subsection{Spatial Variability of Corrections}

[49] For any given grid cell, over all the optimized hours of the $124 \mathrm{~d}$, only one or two values occur with a very high frequency. The most frequent corrections at locations where road traffic plays a key role correspond to an increase in $\mathrm{NO}_{x}$ emissions from 0300 to 0500 and from 0800 to 1000 . Emissions at 0600 and 0700 are decreased in the city of Paris and increased in the suburban areas immediately surrounding the city. Finally, integrating over all optimized hours, the most frequent corrections is an increase of $\mathrm{NO}_{x}$ emissions.

\subsection{Statistical Impact on Concentrations}

[50] In order to quantify the impact of the optimization of $\mathrm{NO}_{x}$ emissions on concentrations, the bias, the random mean square and the correlation between measured and simulated concentrations are computed over all available measurement stations in July and August 1998 and 1999 for the first-guess and the optimized inventories. The difference between the values of the three indicators obtained with the first-guess and with the optimized inventory are displayed in Table 1 for NO mixing ratios. The optimization leads to a significant decrease in the systematic error (bias reduced by more than 33\%) and in the average error (random mean square reduced by $15 \%$ ). Moreover, the time variability of concentrations is better followed with the optimized inventory (correlation increased by more than $28 \%$ ).

[51] Nevertheless, for ozone mixing ratios, the decrease of the bias and random mean square and the increase of the correlation are not significant (less than 3\%) over the whole inverted period. This is linked to the fact that the model and the first-guess inventory have been built in order to forecast summer ozone peaks.

\section{Results for Two Intensive Observation Periods}

[52] We showed that emissions may be inverted in a seasonal way, that is, with the time resolution of the majority of emission inventories used in today's local air 

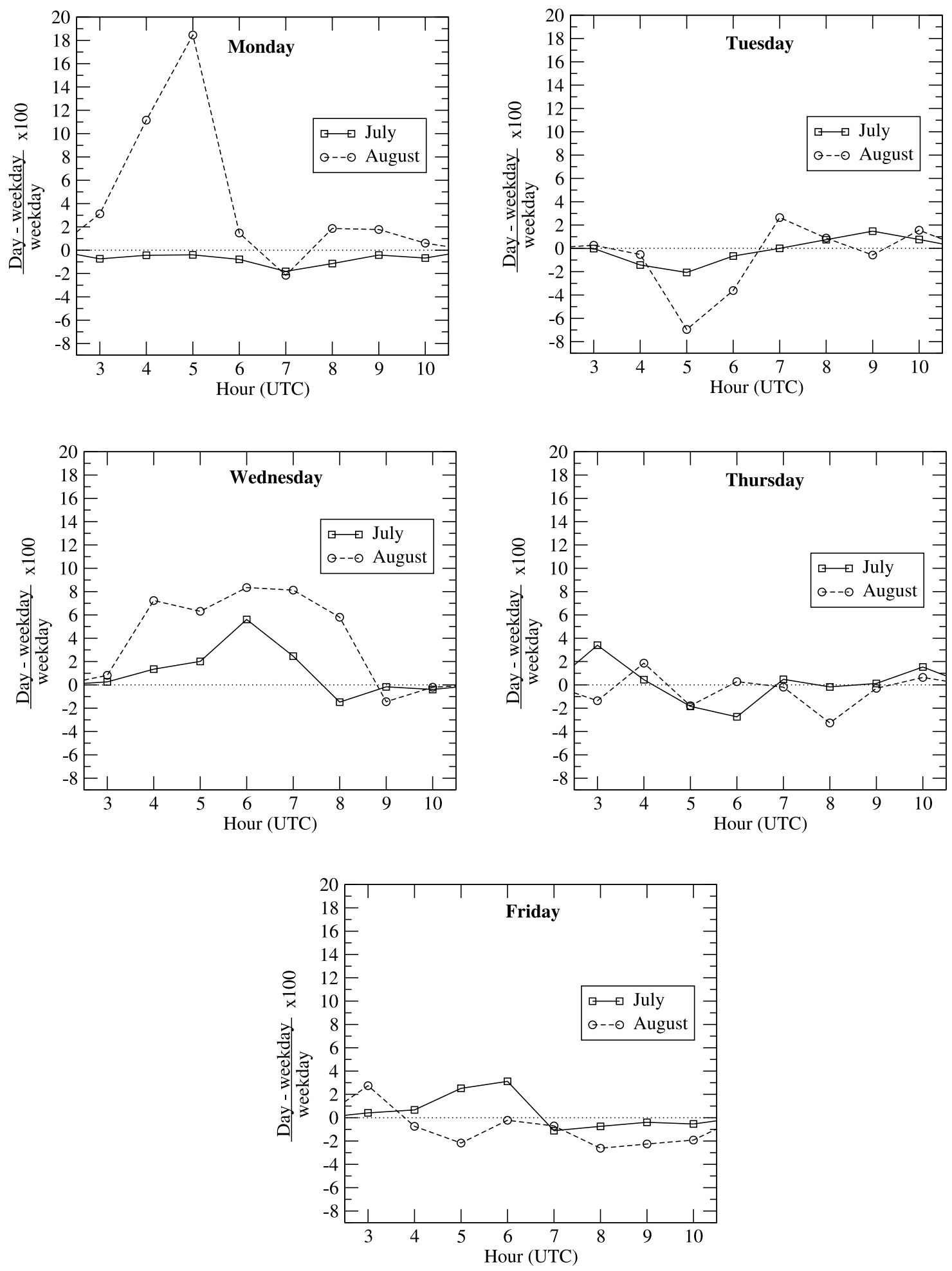

Figure 5. Difference, in percent, between median optimized profiles of NO emissions for each weekday and for the "weekday"-type over July and August 1998 and 1999.

quality studies. In addition, it is interesting to see how the inversion system is able to refine these results through time. To address this point, two Intensive Observations Periods (IOPs) of the ESQUIF campaign are chosen. IOP2 (7 August 1998) and IOP6 (16, 17, and 18 July 1999), are especially suitable for an inversion study since: (1) they correspond to cases representative of typical strong pollution events observed in the Paris area, (2) numerous measurements are available, and (3) they have already been investigated in detail [Blond et al., 2003] and their general pattern is thus well documented, in particular the major role of local emissions [Menut et al., 2000a]. Moreover, IOP6 occurred 
Table 1. Median Values, ppb, Over All Available Measurement Stations of Three Statistical Indicators Over July and August 1998 and 1999 and Difference Due to the Optimization ${ }^{\mathrm{a}}$

\begin{tabular}{lccc}
\hline \multicolumn{1}{c}{ Stat. Indicator $X$} & $X_{\text {first-guess }}[\mathrm{NO}]$ & $X_{\text {optimized }}[\mathrm{NO}]$ & $\Delta X[\mathrm{NO}]$ \\
\hline Bias & $-2.9 \mathrm{ppb}$ & $-1.9 \mathrm{ppb}$ & $-33.2 \%$ \\
RMS & $14.3 \mathrm{ppb}$ & $12.1 \mathrm{ppb}$ & $-15 \%$ \\
Correlation in urban areas & 0.43 & 0.56 & $+28.4 \%$ \\
\hline
\end{tabular}

${ }^{\mathrm{a}} \Delta X=\frac{X_{\text {frist-guess }}-X_{\text {optimized }}}{X_{\text {first }} \text {-guess }} \times 100$. RMS is random mean square.

on Friday, Saturday, and Sunday, that is, days corresponding to the three specific types of days used in building the emission inventory. Since these events have been fully described in previous papers such as Menut [2003] and Vautard et al. [2003a], they will not be discussed in detail here.

\subsection{Results for IOP2}

[53] The spatial distributions of the correction coefficients at 0500 and 0800 UTC are displayed on Figure 6, showing that the pattern of corrections is not homogeneous, neither in time nor in space. At 0500 , the most intense fluxes located downtown are decreased (multiplied by 0.5 to 0.75 ) whereas the intense fluxes located outside the city and upstream are increased (multiplied by 1.25 to 2.75 ). Corrections to the less intense fluxes located outside the city are smaller (coefficients between 0.95 and 1.25). On the contrary, at 0800 , the most intense fluxes are almost unchanged by the optimization with corrections less than $5 \%$ (coefficients between 0.95 and 1.05) whereas less intense fluxes located outside the city are decreased (multiplied by 0.75 to 0.95). The corrections at 0800 are therefore more homogeneous than at 0500 , since all fluxes are decreased.

[54] Since the results differ according to the location, the time evolution of the optimized fluxes is examined at four locations representative of the results obtained in the city and in the suburbs.

[55] Figure 7 displays time series of surface $\mathrm{NO}$ emission fluxes before optimization ("first-guess") and after optimization ("optimized").

[56] In the two suburban areas (relatively urbanized and located about $10 \mathrm{~km}$ from Paris' center) displayed in

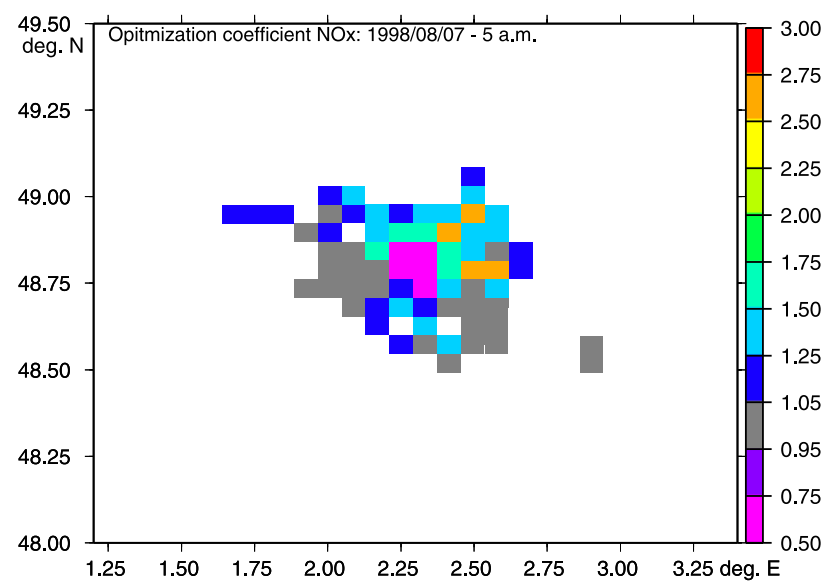

Figures $7 \mathrm{a}$ and $7 \mathrm{~b}$, the moderate morning intensity of $\mathrm{NO}_{x}$ fluxes tends to be increased by the optimization in the northwest and decreased in the southwest. This also appears on Figure 6 (at 0500 and 0800) and confirms the large variability of optimized fluxes.

[57] In the city of Paris, displayed in Figures $7 \mathrm{c}$ and $7 \mathrm{~d}$, the results suggest that $\mathrm{NO}_{x}$ fluxes, mainly due to traffic, may be overestimated during the whole morning in the firstguess inventory. These fluxes are indeed reduced by up to $38 \%$ after optimization. The time series indicate not only that the intensity of the emissions is changed but also that the shape of the time profile is modified. The duration of the morning emission peak is reduced from $5 \mathrm{~h}$ long (from 0500 to 0900 ) to only $2 \mathrm{~h}$ long (from 0800 to 0900 mainly).

[58] This last result is in accordance with the change obtained in the emission inventory for 2000 . This indicates that our inverse modeling methodology is able to diagnose corrections actually applied to operational inventories.

[59] The impact of the optimized emission fluxes on mixing ratios is displayed on Figure 8 for two locations were measurements are available. In the city of Paris, firstguess NO mixing ratios are overestimated compared to measurements: in the southwest part of the city (Figure 8a), simulated mixing ratios between 0600 and 1000 are 1.8 to 3.1 times higher than measured mixing ratios. After the inversion, the time profile of mixing ratios remains the same but their intensity is corrected. For example, the 0700 peak is decreased from $94.5 \mathrm{ppb}$ for the first-guess to $83.7 \mathrm{ppb}$ for optimized mixing ratios, as compared to an analysis of $80.8 \mathrm{ppb}$ and a measurement of $67.6 \mathrm{ppb}$.

[60] In the suburban area (Figure 8b), the measured and first-guess time profiles do not agree neither in intensity nor in evolution. In particular, the measured peak of NO mixing ratios is more intense and occurs earlier than the first-guess one: $123 \mathrm{ppb}$ at 0600 instead of $51 \mathrm{ppb}$ at 0800 . With the optimized emission fluxes, the peak occurs at 0600 and its intensity is $83 \mathrm{ppb}$.

\subsection{Results for IOP6}

[61] The spatial distributions of the correction coefficients are displayed on Figure 9: for each day, the hour at which they are the most spatially heterogeneous is shown. The

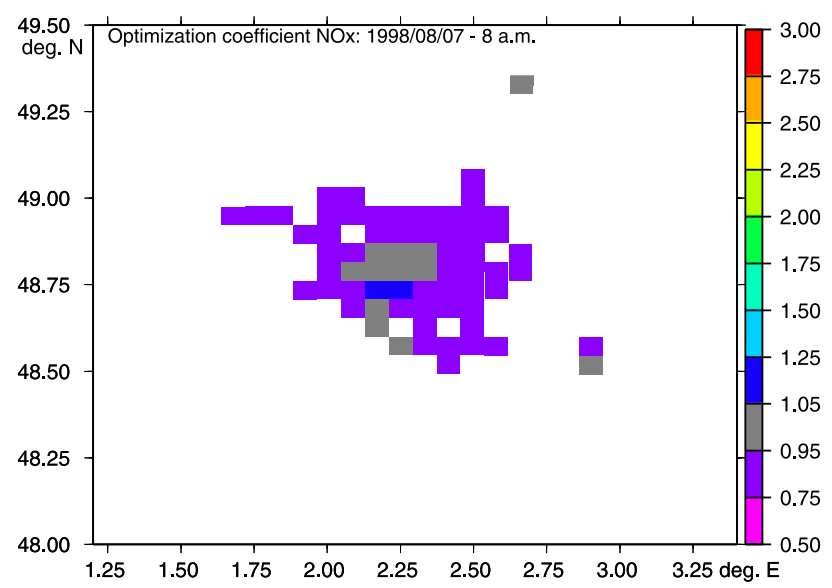

Figure 6. Spatial distribution of correction coefficients for $\mathrm{NO}_{x}$ emission fluxes on 7 August 1998 at 0500 and 0800 UTC. 

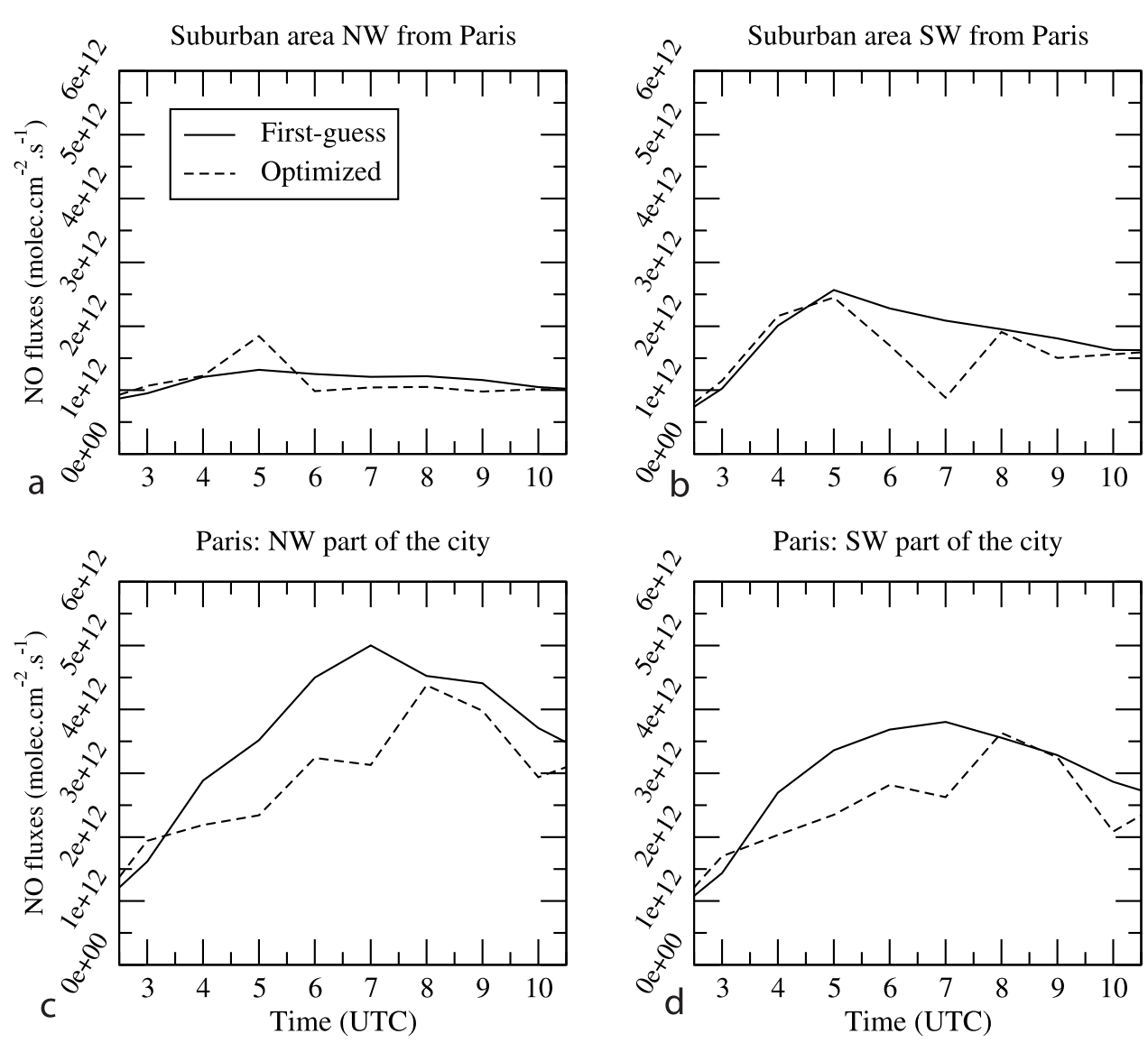

Figure 7. Time series of first-guess and optimized NO emission fluxes at specific locations in the suburbs and in the city of Paris on 7 August 1998.

patterns of corrections are very different from one day to another. Note that these three days (Friday, Saturday, and Sunday) correspond to the three different types of day of the first-guess inventory, with various time profiles applied to emissions.

[62] On Friday at 1000, the optimization leads to a limited change of most of the fluxes (less than $5 \%$, i.e., multiplied by 0.95 to 1.05 ). Only the most intense fluxes, corresponding to the city of Paris, are significantly decreased (multiplied by 0.75 to 0.95$)$.

[63] On Saturday, the results of the optimization differ according to the location. At 0700 , the most intense fluxes located in the city of Paris are multiplied by 1.25 to 1.5 , whereas the intense fluxes located outside the city and downstream are multiplied by only 1.05 to 1.25 . The less intense fluxes are modified by corrections between 0.75 and 1.05. The decrease of the majority of fluxes together with a considerable increase for a few very intense fluxes at 0700 suggest a misestimation in the space and time distribution of the peak emissions, which will be examined with time series (Figure 10).

[64] On Sunday, at 0800 the distribution of the correction coefficients is very homogeneous: all fluxes are decreased (multiplied by 0.5 to 0.75 ) suggesting that the initial emission inventory significantly overestimated the fluxes for this day.

[65] Figure 10 displays time series of surface NO emission fluxes before optimization ("first-guess") and after optimization ("optimized") for the three consecutive days in the city of Paris (Figure 10a) and in a rural area located about $10 \mathrm{~km}$ northeast from Paris (Figure 10b).

[66] As previously stated, on Friday the corrections are relatively small and more or less homogeneous over the whole domain. On the contrary, on Saturday morning, significant changes are obtained after the optimization: compared to the first-guess, the emission peak is more intense ( 5 instead of $3.7 \times 10^{12}$ molec $\mathrm{cm}^{-2} \mathrm{~s}^{-1}$ at 0700 ) but shorter (0700 to 0900 instead of 0500 to 0900 ), due to the decrease of most fluxes (as in the rural area) together with the increase of a few very intense fluxes (as in the city of Paris). This leads to a decrease of the matching NO mixing ratios by more than $40 \%$ (from a first-guess at $71 \mathrm{ppb}$ to $40 \mathrm{ppb}$ after optimization). The overestimation of $\mathrm{NO}$ mixing ratios, diagnosed by comparing the direct simulation to the measurements (not shown here), is therefore almost completely removed after the optimization. The same situation appears on Sunday: a nonobserved concentration peak that is simulated with the first-guess inventory does not occur with the very low optimized emissions (only $2.7 \times$ $10^{12}$ molec cm $\mathrm{cm}^{-2} \mathrm{~s}^{-1}$ from 0900 to 1000 ).

[67] The impact of the optimized emission fluxes on mixing ratios is displayed on Figure 11 for two locations were measurements are available.

[68] On Friday, the time profiles of NO mixing ratios remain the same after the optimization with only small changes in intensity. For example, in the southwest part of 
Paris: SW part of the city

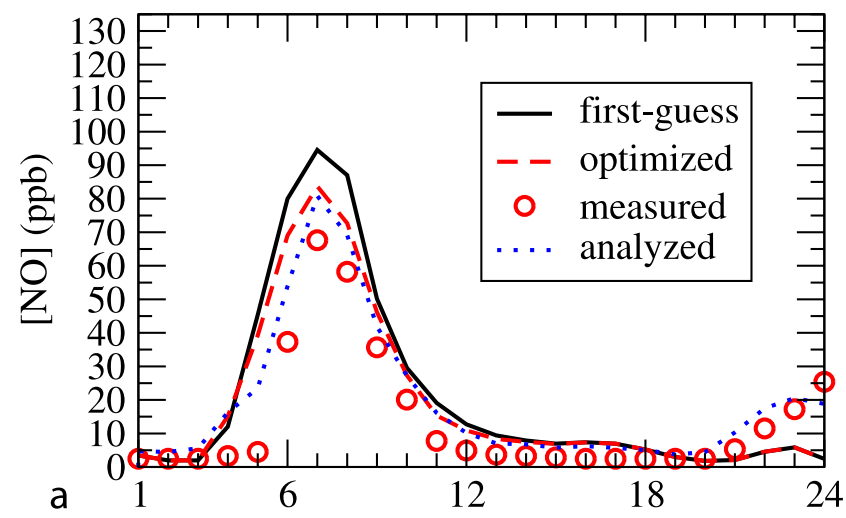

Suburban area: NW from Paris

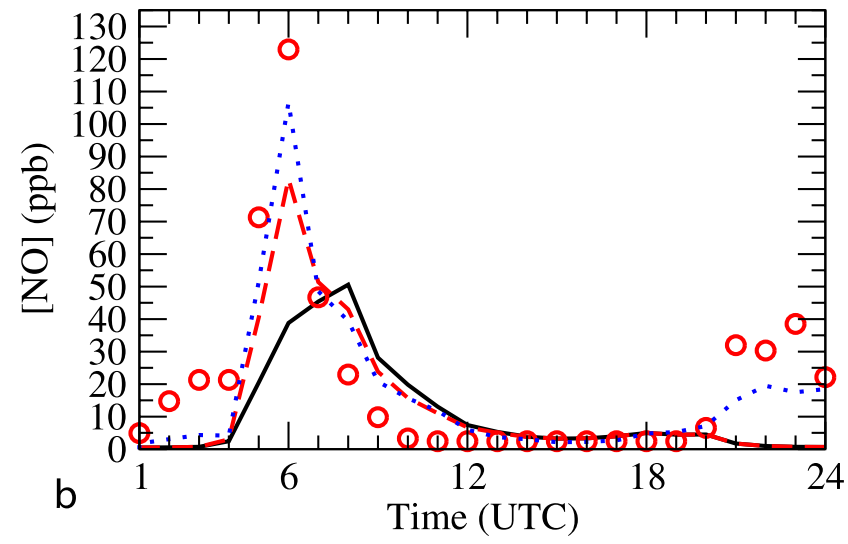

Figure 8. Time series of first-guess, optimized, analyzed, and measured NO mixing ratios at specific locations in the suburbs and in the city of Paris on 7 August 1998.

the city of Paris (Figure 11a), the optimized peak reaches $20 \mathrm{ppb}$ compared to $22 \mathrm{ppb}$ for the first-guess, $23.7 \mathrm{ppb}$ for the measurement, and $21.5 \mathrm{ppb}$ for the analysis.

[69] On Saturday morning, first-guess NO mixing ratios are overestimated compared to measurements. For example in the city (Figure 11a), the first-guess morning peak at $71 \mathrm{ppb}$ is twice as high as the measured one at $35.6 \mathrm{ppb}$. After the optimization, NO mixing ratios match the analysis. The intensity of the peak is reduced by more than $40 \%$ in the city, from $71 \mathrm{ppb}$ to $40 \mathrm{ppb}$ with the optimized emissions and by $50 \%$ in the suburban area, from 39 to $20 \mathrm{ppb}$.

[70] On Sunday morning, the measured and first-guess time profiles do not agree: for example in the suburban area (Figure 11b), a peak is simulated between 0700 and 0800 whereas nothing is observed. In the city, the time profile of optimized mixing ratios matches the measurements and the analysis. In the suburban area, optimized mixing ratios are decreased from a peak at more than $18 \mathrm{ppb}$ from 0700 to 0800 to $13.6 \mathrm{ppb}$ at 0800 .

\subsection{Impact of Optimized $\mathrm{NO}_{x}$ Emissions on Simulated Ozone Concentrations}

[71] In the framework of local air pollution, a major interest of the optimization of emissions is its impact on other key species such as ozone. Modifying $\mathrm{NO}_{x}$ emissions changes the amount of locally available $\mathrm{NO}_{x}$ molecules and can thus affect the chemical regime downstream the sources. In the Paris area, the chemical regime in the plume of the city is most of the time close to the transition between $\mathrm{NO}_{x}$-limited and VOC-limited, with various chemical regimes occurring at the same time at different locations [Sillman et al., 2003]. A slight change in $\mathrm{NO}_{x}$ emissions
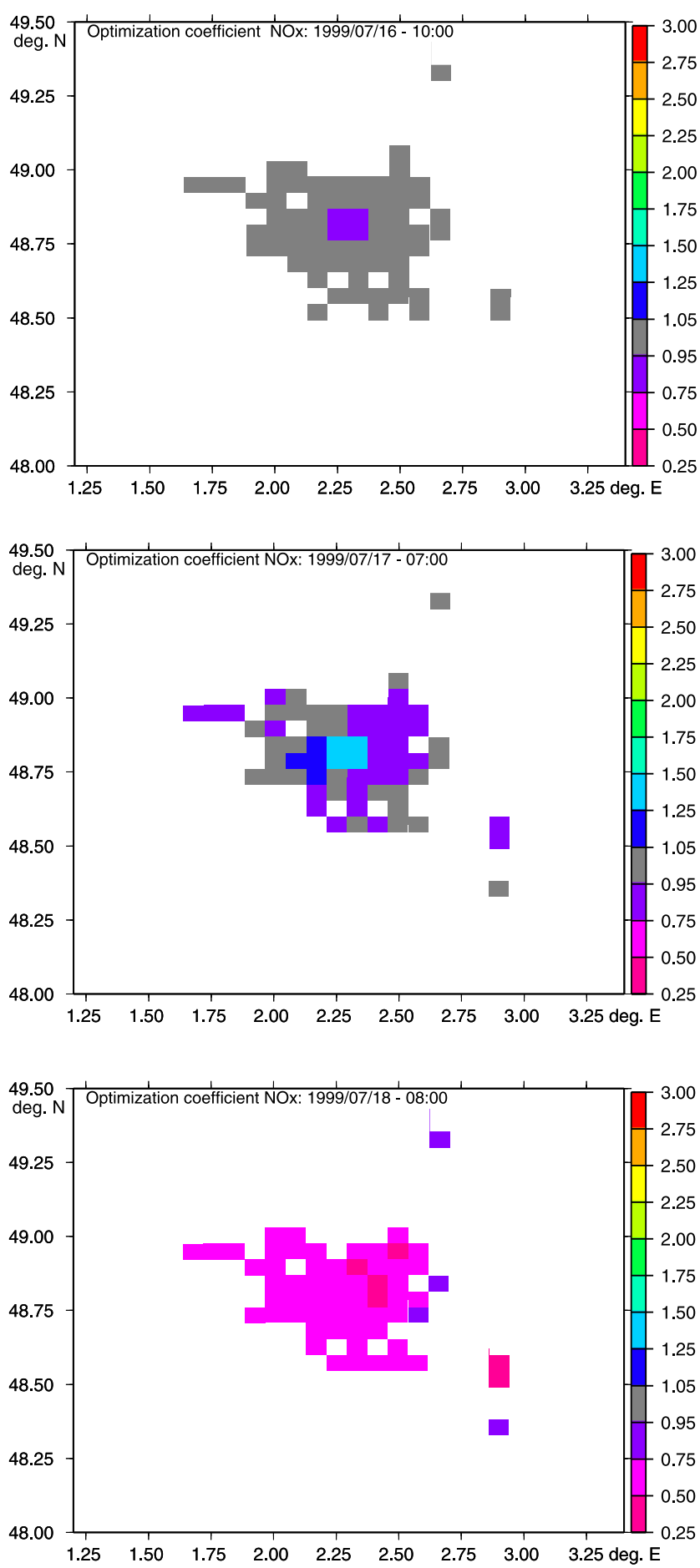

Figure 9. Spatial distribution of correction coefficients for $\mathrm{NO}_{x}$ emission fluxes on 16, 17, and 18 July 1999. 

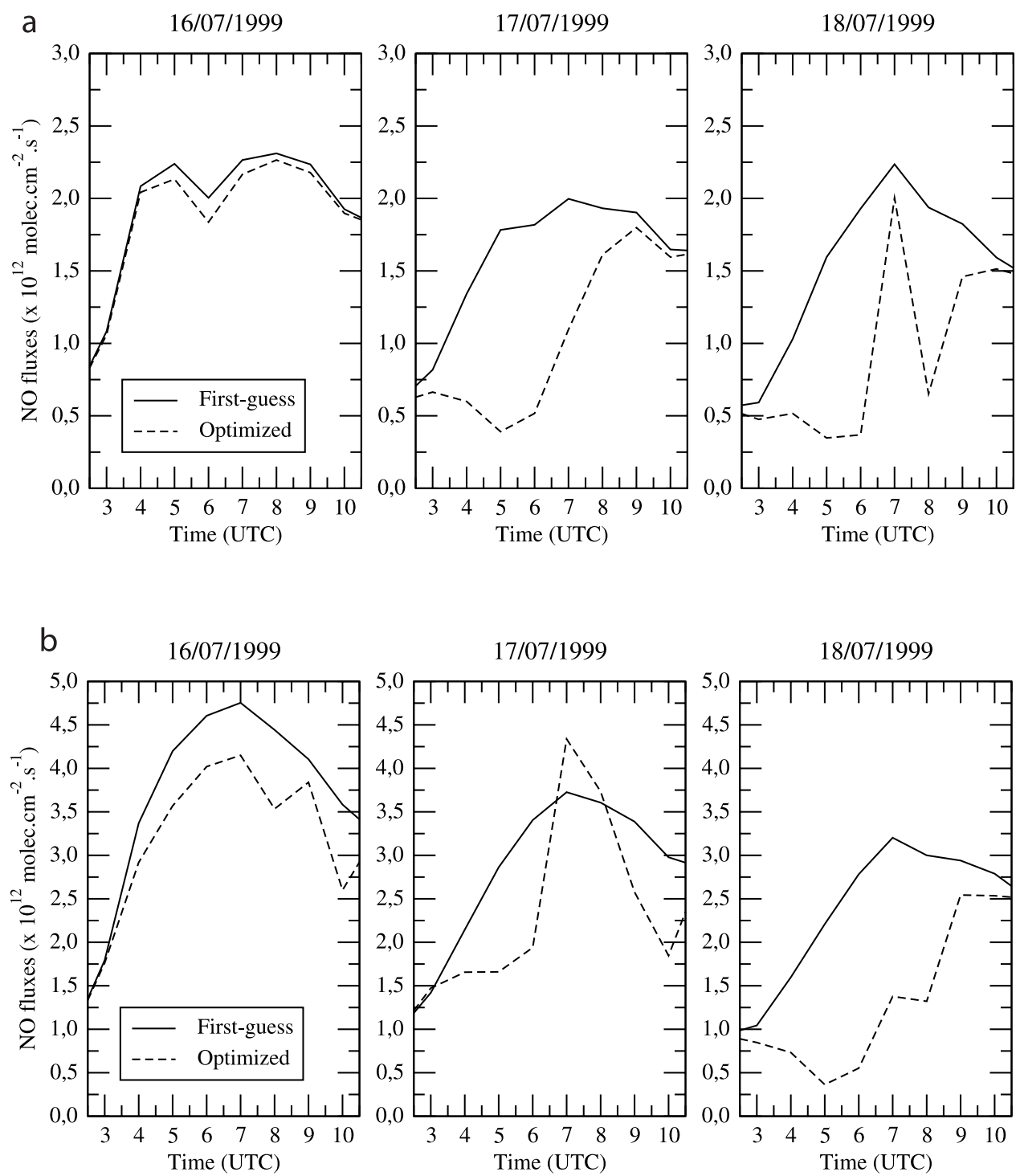

Figure 10. Time series of first-guess and optimized NO emission fluxes on 16, 17, and 18 July 1999 in (a) Paris and (b) a rural area.

may thus dramatically modify the pattern of ozone built up several hours later.

[72] On several days of the studied IOPs, first-guess ozone concentrations simulated in the plume are underestimated. On Figure 12 is displayed a comparison between simulated and measured concentrations in the center of the plume on 7 August 1998: between 1500 and 1800, simulated concentrations are only 85.7 to $51.7 \%$ of measured values. On 16 July 1999, the underestimation of ozone concentrations in the plume is about $10 \mathrm{ppb}$ [Vautard et al., 2003a].

[73] To investigate the impact of the optimization of the emissions on the capacity of the model to reproduce peak ozone concentrations, the difference in ozone surface mixing ratios between simulations performed with the first-guess and the optimized emission inventory are computed on 7 August 1998 and on 16 July 1999 at 1500 , hour close to the daily ozone maximum. This is displayed on Figure 13. On 7 August 1998 (Figure 13a), with the optimized emissions, ozone mixing ratios are increased by 1 to $5 \mathrm{ppb}$ in the center of the plume. The model underestimation in the whole plume is therefore reduced from an average of $8 \%$ at 1500 to only $3 \%$ : the error is then reduced by more than a factor of two. On 16 July 1999 (Figure 13b), the underestimation of ozone mixing ratios in the plume is reduced by 20 to $40 \%$ with the optimized emissions.

[74] In order to assess the impact of the eventual change in simulated chemical regimes induced by the corrections on $\mathrm{NO}_{x}$ emissions, an additional optimization is performed, in which the VOCs to $\mathrm{NO}_{x}$ ratio is kept constant. This is done by applying the same correction coefficient to $\mathrm{NO}_{x}$ and VOCs at all times. The results show that ozone mixing ratios in the plume are decreased by 1 to $2 \mathrm{ppb}$ : the underestimation is then slightly worsened.

[75] These results suggest the VOCs to $\mathrm{NO}_{x}$ ratio probably has to be optimized. However, since no constraints on VOCs is available (very few measurements are regularly performed), the optimization of VOC emissions as such is not possible and the optimization of $\mathrm{NO}_{x}$ emissions alone 
Paris: SW part of the city

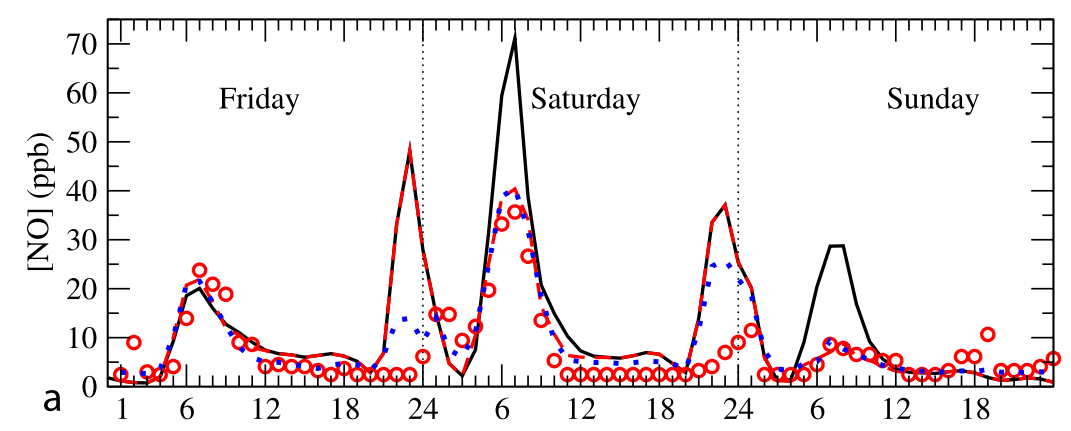

Suburban area NW from Paris

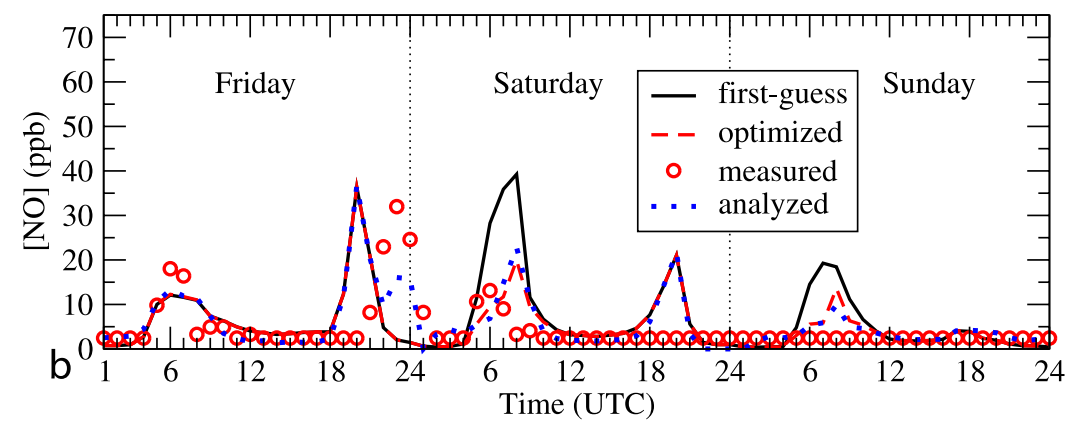

Figure 11. Time series of first-guess, optimized, analyzed, and measured NO mixing ratios at specific locations in the suburbs and in the city of Paris on 16, 17, and 18 July 1999.

remains the only approach to improving emission inventories in the Paris area today.

\section{Conclusions}

[76] In this paper, we used the methodology presented by Pison et al. [2006] to optimize $\mathrm{NO}_{x}$ surface anthropogenic emission fluxes at a local scale in the Paris area. The inversion is based on CHIMERE chemistry transport model and its adjoint simulation, and the choice to use a kriging of measurements method was made in order to access a set of maximal constraints for the inversion. In addition, to further reduce the size of the problem, we developed an original dynamical spatial aggregation method for emission fluxes, that uses both emission and pollutant concentrations and that is updated every hour. This approach was applied and validated for the optimization of morning $\mathrm{NO}_{x}$ emissions in the Paris area during the summers of 1998 and 1999.

[77] Correction coefficients were determined over the Paris area for a 4 month period (July and August 1998 and 1999), for all day and 8 morning hours. This seasonal optimization provides realistic corrections for the total emitted mass as compared to the global estimated error on the emission inventory. We showed that the intense fluxes located in the center of the area are most frequently decreased whereas the less intense periurban fluxes are increased. For the three types of days (weekday, Saturday, and "Sunday or holiday"), the differences between optimized and first-guess profiles are less than 15\%. The comparison between the optimized time profiles for the typical weekday and the five individual days of the week shows that only Mondays and Wednesdays in August have particular characteristics. Finally, the optimized emission inventory significantly improves the statistical performance of the model as described by the bias, the random mean square and the correlation for the simulation of NO mixing ratios.

[78] Moreover, the optimization of the two Intensive Observation Periods of the ESQUIF campaign shows that our methodology can provide realistic correction coefficients for emission fluxes during pollution events, with an hourly resolution. These results highlight the variability of the anthropogenic emissions and suggest that the optimization is able to reduce large differences between simulated

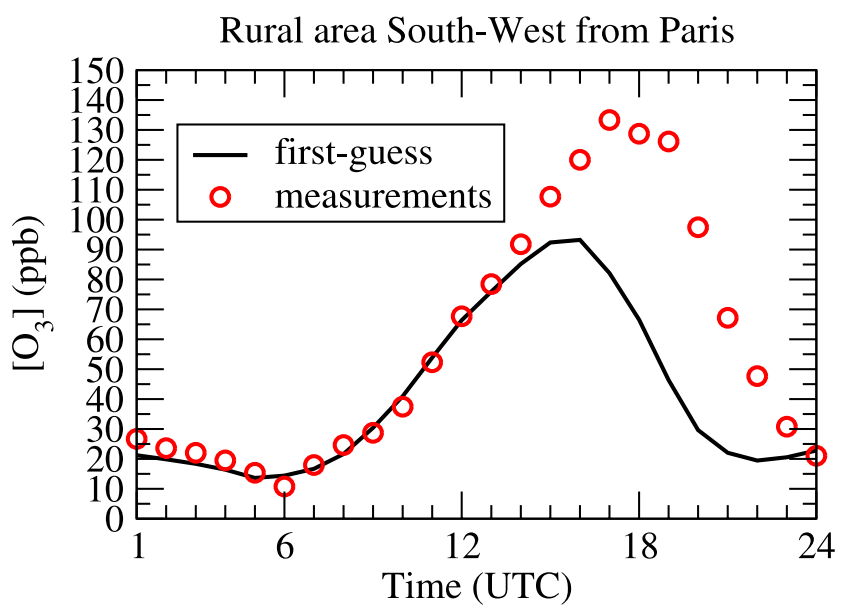

Figure 12. Time series of first-guess and measured ozone mixing ratios in a rural area southwest from the city of Paris (measurement station Rambouillet) on 7 August 1998. 

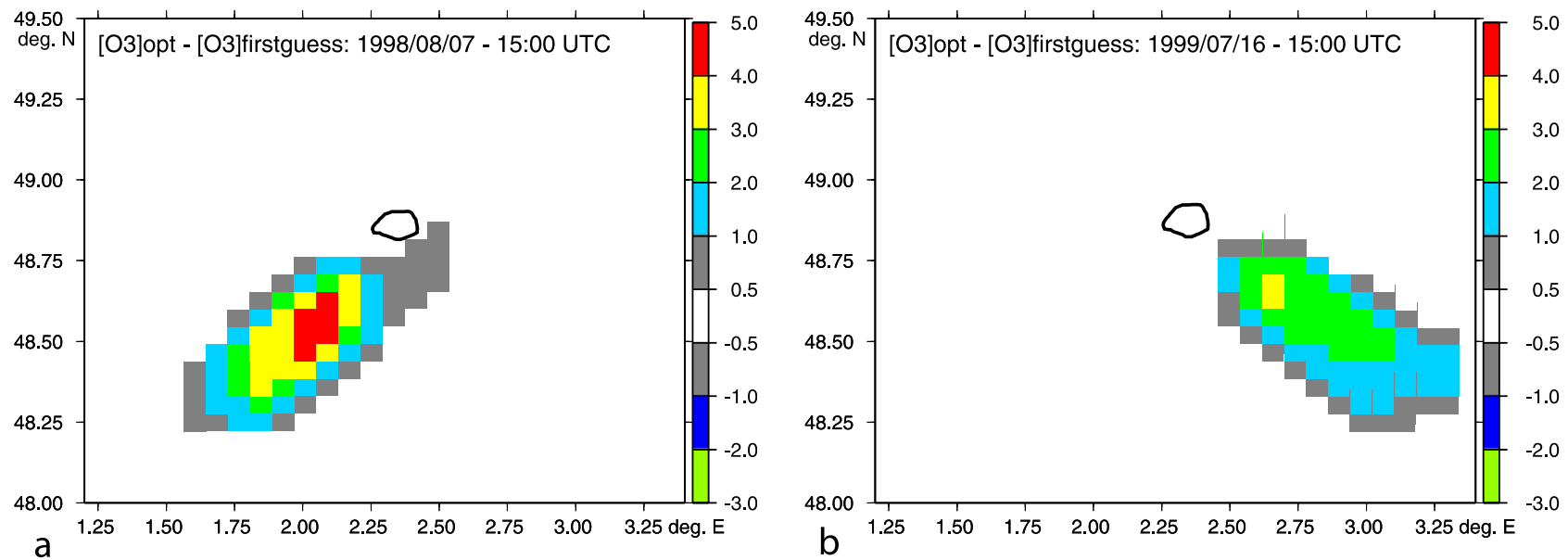

Figure 13. Difference (ppb) between first-guess and optimized ozone mixing ratios at 1500 on 7 August 1998 and 16 July 1999.

and measured concentrations through realistic changes in the emission fluxes.

[79] The methodology used here was elaborated with special attention to be easily applicable to other urban centers, provided that a measurement network is available. The criteria and details of the spatial aggregation would nevertheless have to be adapted to the area's specific characteristics especially in the case of complex terrains (mountainous or coastal areas): direct simulations have to be run to understand the patterns of pollutant plumes and thus to determine the number of areas most suited for the inversion problem. As was done here for the Paris area, two types of results can be obtained: (1) optimized emissions for particular events, such as during the ESCOMPTE campaign in Marseilles (France) (http://medias.obs-mip.fr/ escompte/index) (2) an optimization of the emission inventory for longer periods, that is, a season, particularly useful in areas where emission inventories were established years ago or are not accurate enough as compared to the needs of today's ozone forecasting.

[80] The prospects of this work include chiefly (1) an independent assessment of the optimized inventory and (2) the quantification of its uncertainty. Even if the optimized emissions lead to a decrease of the differences between model and measurements, it should be noted that the method proposed here includes an initial correction of the first-guess simulation introduced by the kriging technique. Using the optimized inventories in other models or in CHIMERE with other sources of meteorological data (RAMS, MM5) to simulate the same pollution events is then envisaged. Our inversion methodology does not make it possible to retrieve the uncertainty of the optimized inventories. This is why the OPTEMI (Optimization of Emissions by Inverse Modeling) project, to which this work is linked, includes interactions between inverse modeling and Monte Carlo simulations as presented by Deguillaume et al. [2007].

[81] Acknowledgments. The authors thank Myrto Valari (IPSL/ LMD), Robert Vautard (IPSL/LSCE), Matthias Beekmann (LISA/CNRS), Gabrielle Petron (NCAR), and Claire Granier (SA/CNRS) for fruitful discussions about the inversion methodology and the results in this paper.
We also thank Cecile Puel and Olivier Duclaux as well as the TOTAL company for the financial support and discussions. This work was done under a TOTAL-CNRS grant and in the framework of the PRIMEQUAL2 project OPTEMI supported by the French Ministry of Environment.

\section{References}

Beekmann, M., and C. Derognat (2003), Monte-Carlo uncertainty analysis of a regional-scale transport chemistry model constrained by measurements from the Atmospheric Pollution Over the Paris Area (ESQUIF) campaign, J. Geophys. Res., 108(D17), 8559, doi:10.1029/2003JD003391.

Bergamaschi, P., R. Hein, M. Heinmann, and P. Crutzen (2000), Inverse modeling of the global $\mathrm{CO}$ cycle: 1 . Inversion of $\mathrm{CO}$ mixing ratio, J. Geophys. Res., 105(D2), 1909-1927.

Blond, N., L. Bel, and R. Vautard (2003), Three-dimensional ozone data analysis with an air quality model over the Paris area, J. Geophys. Res., 108(D23), 4744, doi:10.1029/2003JD003679.

Bousquet, P., P. Ciais, P. Peylin, and P. Monfray (1999), Inverse modeling and annual atmospheric $\mathrm{CO}_{2}$ sources and sinks: 1 . Method and control inversion, J. Geophys. Res., 104(D21), 26,161-26,178.

Chang, M., D. Hartley, and W.-L. Chang (1996), Inverse modeling of biogenic isoprene emissions, Geophys. Res. Lett., 23(21), 3007.

Chang, M., D. Hartley, C. Cardelino, D. Haas-Laursen, and W. Chang (1997), On using inverse methods for resolving emissions with large spatial inhomogeneities, J. Geophys. Res., 102(D13), 16,023-16,036.

Daescu, D., A. Sandu, and G. Carmichael (2003), Direct and adjoint sensitivity analysis of chemical kinetic systems with kpp: Ii-numerical validation and applications, Atmos. Environ., 37, 5097-5114.

Deguillaume, L., M. Beekmann, and L. Menut (2007), Bayesian monte carlo analysis applied to regional-scale inverse emission modeling for reactive trace gases, J. Geophys. Res., 112, D02307, doi:10.1029/ 2006JD007518.

Enting, I. (2002), Inverse Problems in Atmospheric Constituent Transport, 394 pp., Cambridge Univ. Press, New York.

Gilbert, J.-C., and C. Lemaréchal (1989), Some numerical experiments with variable-storage quasi-Newton algorithms, Math. Progr., 45, 407-435.

Gurney, K., Y.-H. Chen, T. Maki, S. Kawa, A. Andrews, and Z. Zhu (2005), Sensitivity of atmospheric $\mathrm{CO}_{2}$ inversions to seasonal and interannual variations in fossil fuel emissions, J. Geophys. Res., 110, D10308, doi:10.1029/2004JD005373.

Hartley, D., and R. Prinn (1993), On the feasibility of determining surface emissions of trace gases using an inverse method in a three-dimensional chemical transport model, J. Geophys. Res., 98, 5183-5198.

Hein, R., P. J. Crutzen, and M. Heimann (1997), An inverse modeling approach to investigate the global atmospheric methane cycle, Global Biogeochem. Cycles, 11, 43-76.

Houweling, S., T. Kaminski, F. Dentener, J. Lelieveld, and M. Heinmann (1999), Inverse modeling of methane sources and sinks using the adjoint of a global transport model, J. Geophys. Res., 104(D21), 26,137-26,160.

Kaminski, T., and M. Heimann (2001), Inverse modeling of atmospheric carbon dioxide fluxes, Science, 294, 259.

Konovalov, I., M. Beekmann, A. Richter, and J. Burrows (2005), Inverse modelling of the spatial distribution of $\mathrm{NO}_{x}$ emissions on a continental scale using satellite data, Atmos. Chem. Phys. Disc., 5, 12,641-12,695. 
Kühlwein, J., and R. Friedrich (2000), Uncertainties of modelling emissions from road transport, Atmos. Environ., 34, 4603-4610.

Mahowald, N., R. Prinn, and P. Rasch (1997), Deducing ccl3 f emissions using an inverse method and chemical transport models with assimilated winds, J. Geophys. Res., 102, 28,153-28,168

Mendoza-Dominguez, A., and A. Russell (2001), Estimation of emission adjustments from the application of four-dimensional data assimilation to photochemical air quality modeling, Atmos. Environ., 35, 2879-2894.

Menut, L. (2003), Adjoint modelling for atmospheric pollution processes sensitivity at regional scale during the ESQUIF IOP2, J. Geophys. Res., 108(D17), 8562, doi:10.1029/2002JD002549.

Menut, L., R. Vautard, M. Beekmann, and C. Honoré (2000a), Sensitivity of photochemical pollution using the adjoint of a simplified chemistrytransport model, J. Geophys. Res., 105(D12), 1,5379-15,402.

Menut, L., et al. (2000b), Measurements and modelling of atmospheric pollution over the Paris area: An overview of the ESQUIF Project, Ann. Geophys., 18(11), 1467-1481.

Mulholland, M., and J. Seinfeld (1995), Inverse air pollution modelling of urban-scale carbon monoxide emissions, Atmos. Environ., 29, 497-516.

Müller, J.-F., and T. Stavrakou (2005), Inversion of CO and $\mathrm{NO}_{x}$ emissions using the adjoint of the IMAGES model, Atmos. Chem. Phys., 5, 11571186.

Pétron, G., C. Granier, B. Khattatov, J.-F. Lamarque, V. Yudin, J.-F. Müller, and J. Gille (2002), Inverse modeling of carbon monoxide surface emissions using Climate Monitoring and Diagnostics Laboratory network observations, J. Geophys. Res., 107(D24), 4761, doi:10.1029/ 2001JD001305.

Pétron, G., C. Granier, B. Khattatov, V. Yudin, J.-F. Lamarque, L. Emmons, J. Gille, and D. Edwards (2004), Monthly CO surface sources inventory based on the 2000-2001 MOPITT satellite data, Geophys. Res. Lett., 31, L21107, doi:10.1029/2004GL020560.

Pison, I. (2005), Modélisation inverse pour l'optimisation des sources primaires de pollution atmosphérique à l'échelle régionale, in Chimie de la Pollution Atmosphérique et Physique de l'Environnement, 188 pp., Univ. Paris XII, Val-de-Marne, France.

Pison, I., and L. Menut (2004), Quantification of the impact of aircraft traffic emissions on tropospheric ozone over Paris area, Atmos. Environ. $38(7), 971-983$.

Pison, I., L. Menut, and N. Blond (2006), Inverse modeling of emissions for local photo-oxidant pollution: Testing a new methodology with kriging constraints, Ann. Geophys., 24, 1523-1535.

Prinn, R., and D. Hartley (1995), Inverse methods in atmospheric chemistry, in Progress and Problems in Atmospheric Chemistry, chap. 6, pp. 172 197, World Sci., Tokyo.
Quélo, D., V. Mallet, and B. Sportisse (2005), Inverse modeling of NO emissions at regional scale over Northern France: Preliminary investigation of the second-order sensitivity, J. Geophys. Res., 110, D24310, doi:10.1029/2005JD006151.

Rödenbeck, C., S. Houweling, M. Gloor, and M. Heimann (2003), $\mathrm{CO}_{2}$ flux history 1982-2001 inferred from atmospheric data using a global inversion of atmospheric transport, Atmos. Chem. Phys., 3, 1919-1964.

Sandu, A., D. Daescu, and G. Carmichael (2003), Direct and adjoint sensitivity analysis ofchemical kinetic systems with kpp: Part i-Theory and software tools, Atmos. Environ., 37, 5083-5096.

Schmidt, H., and D. Martin (2003), Adjoint sensitivity of episodic ozone in the Paris area to emissions on the continental scale, J. Geophys. Res., 108(D17), 8561, doi:10.1029/2001JD001583.

Schmidt, H., C. Derognat, R. Vautard, and M. Beekmann (2001), A comparison of simulated and observed ozone mixing ratios for the summer of 1998 in western Europe, Atmos. Environ., 35, 6277-6297.

Sillman, S., R. Vautard, L. Menut, and D. Kley (2003), $\mathrm{O}_{3}-\mathrm{NO}_{x}-\mathrm{VOC}$ sensitivity indicators in Paris: Results from models and ESQUIF measurements, J. Geophys. Res., 108(D17), 8563, doi:10.1029/2002JD001561.

Talagrand, O. (1997), Assimilation of observations: an introduction, J. Meteorol. Soc. Jpn., 75(1B), 191-209.

Talagrand, O., and P. Courtier (1987), Variational assimilation of meteorological observations with the adjoint vorticity equations, part I - theory, O. J. R. Meteorol. Soc., 113, 1311-1328.

Vautard, R., M. Beekmann, J. Roux, and D. Gombert (2001), Validation of a hybrid forecasting system for the ozone concentrations over the Paris area, Atmos. Environ., 35, 2449-2461.

Vautard, R., et al. (2003a), A synthesis of the Air Pollution Over the Paris Region (ESQUIF) field campaign, J. Geophys. Res., 108(D17), 8558, doi:10.1029/2003JD003380.

Vautard, R., et al. (2003b), Paris emission inventory diagnostics from ESQUIF airborne measurements and a chemistry transport model, J. Geophys. Res., 108(D17), 8564, doi:10.1029/2002JD002797.

Wang, Y., and S. Bentley (2002), Development of a spatially explicit inventory of methane emissions from Australia and its verification using atmospheric concentration data, Atmos. Environ., 36, 4965-4975.

Wang, Y., M. McElroy, T. Wang, and P. Palmer (2004), Asian emissions of $\mathrm{CO}$ and $\mathrm{NO}_{x}$ : Constraints from aircraft and Chinese station data, J. Geophys. Res., 109, D24304, doi:10.1029/2004JD005250.

G. Bergametti and I. Pison, Laboratoire Inter-Universitaire des Systèmes Atmosphériques, Université Paris 12-CNRS, Créteil, F-94010 France.

L. Menut, Laboratoire de Météorologie Dynamique, Ecole Polytechnique, Palaiseau, F-91190 France. (menut@lmd.polytechnique.fr) 